\title{
Exploring the Instructional Techniques and Learning Strategies: Towards a More Synchronized Model of Vocabulary Acquisition
}

\author{
Rasheega Abdel Galeel Mohammed Salih \\ Al Bahah University/ Saudi Arabia, Department of English language Supervisor, Dr. Ali Khalid Mudawi \& Dr. Salah Adam Eldouma
}

\begin{abstract}
This study investigates the methods and techniques used in teaching and learning vocabulary, and the possibility to synchronize them for the purpose of maximizing the effectiveness of vocabulary learning. The sample of the study consisted of 200 (male and female) students in Sudan University of Science and Technology (SUST) chosen from first and second year in five colleges (languages, science, business studies, radiological science and medical laboratories). The second group was teachers of English language selected from two representative universities which are Sudan University of Science and Technology and AL Neelain University. The instruments used for data collection were two questionnaires; one for the teachers and the other for the students. Data were analyzed statistically by statistical package for the social sciences (SPSS). The findings showed that teachers are satisfied with the vocabulary they teach to their students in terms of appropriateness, usefulness and variety. However, they were not satisfied with it in terms of quantity. The majority of teachers used different types of tests to evaluate the students' mastery of vocabulary knowledge. Also the study showed that the students employ different learning styles when learning vocabulary and that the teaching methods of vocabulary and the learning strategies of vocabulary can match each other. In other words, making the teaching methods correspond to the learning strategies. The study concluded with some recommendations offered to EFL learners, teachers of English and syllabus designers to consider the most effective strategies used in the teaching learning of vocabulary.
\end{abstract}

Keywords: vocabulary, acquisition, learning strategies, validity

\section{Introduction}

Vocabulary acquisition is increasingly viewed as categorical to language learning. However, there is much argument on the influence of different methods for presenting vocabulary items. Moreover, learning vocabulary is often considered as a hard procedure. Without grammar very little can be conveyed, without vocabulary nothing can be conveyed (Thornbury2002).

There are many factors occur to play a role in vocabulary development, though the role is not always clearly understood. One of these factors is to do with information, in other words, the process in which vocabulary appears to learners, for example through teacher, presentation, and reading words in texts. The other factors are to do with storing, organizing and establishing vocabulary in the mental lexical and how to recall it when it is needed.

Vocabulary is the knowledge of words and word meanings. As Steven Stahl (2005) puts it, "Vocabulary knowledge is the knowledge of a word not only implies a definition, but also implies how that word fits into the world." Vocabulary knowledge is not something that can ever be fully mastered; it is something that expands and deepens over the course of a lifetime. Instruction in vocabulary includes far more than looking up words in a dictionary and using the words in a sentence. Vocabulary is acquired incidentally through indirect exposure to words and intentionally through explicit instruction in specific words and word-learning strategies.

Vocabulary acquisition is categorical to academic development. Not only do students need a rich body of word knowledge to succeed in basic skill area, they also need a specialized vocabulary to learn material of content area.
A foundation of knowledge must be in place early if students are going to perform successfully in their university study. Vocabulary instruction includes not only looking up words in a dictionary but also using the words in a sentence. Vocabulary is acquired incidentally through indirect exposure to words and intentionally through direct instruction in special words and word-learning strategies.

Learning students might even have a receptive knowledge of a broad scope of vocabulary. That to say they can realize the item and realize it's naturally restricted and this is one of the areas that needs greater consideration. At this stage we are interested not only with students understanding of the meaning of words, but also with their ability to use these words appropriately, taking in to accounts some factors such as oral / written use of language : degree of formality, style, idiom and others.

The purpose of this study is to investigate the methods of vocabulary teaching techniques and vocabulary learning strategies in order to be synchronized, also the study explores the sources of some difficulties encountered by both teachers in teaching vocabulary techniques and learners in learning vocabulary strategies. The study suggests solutions in hope of helping students to be aware of their learning strategies and learning styles, training teachers to discover the learning styles and learning strategies of the students. Syllabus designers should include sections about learning styles, learning strategies in their text books.

\section{Statement of the Problem}

One major area in foreign language learning is that of vocabulary acquisition. Theorists and practitioners alike have been searching for a method that makes this task 


\section{International Journal of Science and Research (IJSR) \\ ISSN (Online): 2319-7064}

Index Copernicus Value (2013): 6.14 | Impact Factor (2014): 5.611

feasible, rewarding and more effective for both teachers and learners. In order for this to be realized in practical terms, both the methods followed by teachers in vocabulary instruction and the strategies employed by the learners in vocabulary acquisition have to be well in harmony. If the teachers teaching and the learners learning are on 'the same wavelength', then chances are that the resultant outcome will presumably be beneficial to both teachers and learners.

The problem which the present study attempts to investigate is whether or not the teaching methods of vocabulary and the learning strategies of vocabulary can match each other. In other words, the study will try to explore the possibility of making the teaching methods correspond to the learning strategies. It will try to find out if the channels of communication in the teaching/learning process with respect to vocabulary acquisition are open between the two parties the teachers and the learners.

\section{Research Questions}

The study will try to provide some answers to the following sets of questions:

The first set of questions concerns the teachers' views and practice.

1) To what extent do teachers think that the vocabulary they teach to students is appropriate, useful, enough and covers a good range of registered?

2) To what extent do teachers believe that the vocabulary they teach matches the level of the students in terms of clarity?

3) What is/are the best method(s) the teachers follow in order to teach vocabulary?

4) To what extent do teachers believe that vocabulary practice is integrated with language skills?

5) What strategies do teacher follow in order to help the students recall words?

6) How do teachers test the students' knowledge of vocabulary?

The second set of questions concerns the students:

1) How do students learn new words?

2) What is their favorite ways of learning new words?

3) Which is their favorite place for learning new words?

4) How do students behave when they encounter an unfamiliar word?

5) What are their preferred activities for practicing new words?

6) What strategies do students employ when they try to recall a newly learnt word?

7) How do students pick up (informally) new words?

The third set of questions concerns the harmony in teaching techniques and learning strategies:

1) What are the areas that both aspects (teaching techniques and learning strategies) are concerned with?

2) To what extent can teaching techniques correspond to learning strategies?

\section{Hypotheses of the Study}

The study hypotheses the following:

1) In terms of quantity and quality, the body of vocabulary taught to the students is sufficient.

2) In terms of presentation, practice and evaluation of vocabulary knowledge, teachers use adequate techniques.

3) Students employ certain strategies in order to deal with unfamiliar words or recall newly learnt words?

4) Students informally pick up words through a number of ways.

5) Teaching techniques and learning strategies correspond considerably.

\section{Significance of the Study}

The study hopes to be of a great importance to teachers, learners, researchers and syllabus designers in a way that it gives an account of the most effective strategies used in teaching vocabulary. Furthermore, the study will provide syllabus designers with data concerning the principles upon which lexical items can be graded, sequenced in a textbook.

\section{Objectives of the Study}

The main objectives of this study are the following:

1) To explore the methods and techniques used in teaching and learning vocabulary.

2) To provide teachers with the effective techniques in teaching vocabulary and learners with the effective strategies in vocabulary acquisition.

3) To verify to what extend vocabulary can be developed through the synchronization of teaching techniques and learning strategies.

\section{Methodology}

The researcher has given a description of the way in which she presented the research.

The subjects of the study were chosen from the first and second year university students who were studying English in different specialization. The researcher used two questionnaires as tools for collecting data. The design of the tools has been described, and the validity and reliability of these tools were discussed. The procedures of data are also described in details.

\section{a) The Subjects of the Study}

The subject of this study is divided into groups. The first group was composed of the students that belong to different fields of specialization in Sudan University of Science and Technology (SUST). The students who answered the questionnaire were randomly chosen from first and second year in five colleges (languages, science, business studies, radiological science and medical laboratories.)

The second group was composed of teachers of the English language selected from two representative universities was Sudan University of Science and Technology and AL Neelin 


\section{International Journal of Science and Research (IJSR) \\ ISSN (Online): 2319-7064 \\ Index Copernicus Value (2013): 6.14 | Impact Factor (2014): 5.611}

University. The number s of chosen samples of the study was thirty teachers and 200 students.

\section{b) The tools of the study}

In this study two questionnaires were employed. The questions and statements were used in both questionnaires concerning vocabulary teaching methods and vocabulary learning strategies. One questionnaire was for teachers of English language in Sudan University of Science and Technology and Alneelin University. The other was for students who were studying in Sudan University of Science and Technology.

\section{c) Teachers' questionnaire}

This questionnaire consists of twenty questions. Teachers were asked to determine their attitudes towards twenty statements and questions by ticking the right options. The options given were ranging from yes, no, and to some extent. The statements in the questionnaire will be used to collect the required data. They are organized to serve the purposes of the study.

\section{d) Students' questionnaire}

The Students' questionnaire included the statements and questions about the problems that students faced while learning English in their university. These difficulties were related to their learning and teaching strategies. Also, it includes aspects such as preferred activities and places for vocabulary learning. Strategies the students use in learning vocabulary. The items of the questionnaire were designed to serve the purposes of the study.

\section{e) The procedures of the study}

The questionnaires used in this study (one for EFL students and other for EFL teachers) were designed in accordance with the need and the importance of the instrument in relation to the purpose of the research.

The two tools were described to the subjects in the above mentioned universities to collect the necessary data for the study. As for the teachers' questionnaire, some helpful teachers supported the researcher and helped in distributing the questionnaires. As for the students' questionnaire, also some colleagues helped the researcher during English classes to draw the attention of the students and give instructions where necessary. Each student was asked to complete the questionnaire individually.

\section{f) Validity}

There were two steps that the researcher adopted in order to certify the validity of the tools. Firstly the questionnaires were given to a number of experts from Sudan University of Science and Technology and from different universities. The experts helped to construct these tools.

The experts from all the mentioned fields helped to construct these tools and they recommended some necessary changes that ought to be taken into consideration in the final researchers' versions tools. They accepted the appropriateness of the items to measure the purposes they were designed for. Secondly, the tools were given to a number of teachers who did not face any problem in answering the questions. Finally, the results of the questionnaires were analyzed statically to illustrate the validity of the tools.

\section{g) Reliability}

The issues reaffirmed the reliability of the tools in following points:

- Using the computer program (SPSS) to analyze data statically.

- The selection of the subjects was based on a random choice.

- The adequacy of the scores will reaffirm the research's purposes.

\section{Finding}

From the teachers' questionnaire, it is clear that the teachers use many techniques for teaching vocabulary such as:

1) Contextualization of words

2) Using realia

3) Using a situation

4) Board illustrations

5) Developing photographic memories

6) Using mental repetition

7) Using mental mnemonics

8) Establishing self-study habits

9) Exposure to language in the media

From the students' questionnaire, it is clear that the students use many strategies for learning vocabulary such as:

1) Using dictionaries

2) Guessing meaning from context

3) Writing a word several times

4) Repeating a word several times

5) Listening to words from cassettes

6) Using visual aids

7) Compiling wordlists

8) Using lexical sets

\section{Recommendations}

Based on the results and findings of the study the following recommendations are given:

1) Attention has to be paid that vocabulary teaching techniques and vocabulary learning strategies have to be synchronized.

2) Teachers have to be trained to discover how to use the learning styles and learning strategies of the students. They are expected to do their best to make their teaching methods go in harmony with the learning strategies and learning styles of the students.

3) Students have to be aware of their learning strategies and learning styles.

4) Good learner strategies have to be identified and explicitly taught to the students.

5) Textbooks have to include sections about learning styles, learning strategies and learning to learn. 


\section{International Journal of Science and Research (IJSR) \\ ISSN (Online): 2319-7064}

Index Copernicus Value (2013): 6.14 | Impact Factor (2014): 5.611

6) Vocabulary taught to the students has to suit their levels and needs.

7) Vocabulary items must be well selected graded and presented.

8) Vocabulary practice activities have to be incorporated in the body of the textbooks and should be integrated with the other skills.

9) Vocabulary learning should not be restricted to the classroom. Students have to be trained to how to create their own opportunities for vocabulary learning in informal settings outside the classroom.

10) The rich resources of the Internet and the Information and Communications Technology have to be put to advantage.

\section{Suggestions for further research}

Throughout this study, a number of areas drew the attention of the researcher as potential topics for further research. These include:

- The expansion of the students' active vocabulary by transference from their passive vocabulary.

- The role of schemata in learning vocabulary.

- Ways of engaging the students in the selection, gradation and presentation of vocabulary.

- Developing matrices of scope and sequence for lexical items that can work as a purpose-made General Service List for textbook writing at university level.

\section{References}

[1] Beck, I.L., McKeown, M.G., \& Kucan, L.Bringing words to life: Robust vocabulary instruction. New York: Guilford Press (2002).

[2] Ebbers, S.M. Vocabulary through Morphemes: Suffixes, Prefixes and Roots for Intermediate Grades.) Longmont, CO: Sopris West (2004)

[3] Ellis, N. Consciousness in second language learning: Psychological perspectives on the role of conscious processes in vocabulary acquisition. AILA Review, 11, 37-56. (19

[4] Graves, M .A vocabulary Program to Complement and Bolster a middle-grade Comprehension Program. In B. (2000)

[5] Hedg.e.Teaching and Learning in the Language Classroom. Oxford, (2009)

[6] National Reading Panel. Teaching children to Read: An evidence-based assessment of scientific research literature on reading and its implications for reading instruction. Bethesda, MD: National Institutes of Health (2000).

[7] Read, J. Assessing vocabulary. Cambridge: Cambridge University Press (2000)

[8] Stahl, S.A., Richek, M.A., \& Vandevier, R.J. Learning Meaning Vocabulary through Listening: A sixth grade replication. In J.Zutell\& S. McCormick (Eds.) Learner factors/teacher factors: Issues in literacy research instruction. The Fortieth Yearbook of the National Reading Conference, Chicago, IL (1991)

[9] Thornbury, $t$ : How to Teach Vocabulary, Longman,(2005 )
[10] Schmitt, N. Vocabulary in Language Teaching. Cambridge: Cambridge University Press (2000). 